\title{
Meal-induced insulin sensitization in conscious and anaesthetized rat models comparing liquid mixed meal with glucose and sucrose
}

\author{
Parissa Sadri ${ }^{1}$, Maria A. G. Reid ${ }^{1}$, Ricardo A. Afonso ${ }^{2}$, Joshua Schafer ${ }^{1}$, Dallas J. Legare ${ }^{1}$, \\ M. Paula Macedo ${ }^{2}$ and W. Wayne Lautt ${ }^{1 *}$ \\ ${ }^{1}$ Department of Pharmacology \& Therapeutics, Faculty of Medicine, University of Manitoba, A210 - 753 McDermot Avenue, \\ Winnipeg, Manitoba, Canada, R3E OT6 \\ ${ }^{2}$ Departamento de Fisiologia - FCM-UNL, Campo Martires da Patria 130, 1169-056 Lisbon, Portugal
}

(Received 1 July 2005 - Revised 14 September 2005 - Accepted 10 October 2005)

\begin{abstract}
We have recently shown that meal-induced insulin sensitization (MIS) occurs after feeding and decreases progressively to insignificance after $24 \mathrm{~h}$ of fasting and is caused by action of a hepatic insulin sensitizing substance (HISS). In order to carry out quantitative studies of MIS, some standardized meal intake is required. Our objective was to establish animal models to be tested in both the conscious and anaesthetized state using intragastric injection of liquid meals in order to quantify MIS. Insulin sensitivity was assessed before and 90 min after the meal using the rapid insulin sensitivity test (RIST) which is a transient euglycaemic clamp. Rats tested in the conscious state were instrumented under anaesthesia 6-9 d prior to testing with catheters in the carotid artery, jugular vein and stomach. Meals, injected into the stomach, consisted of a liquid mixed meal, sucrose, glucose or water. The glucose sequestration in response to insulin increased by $90 \%$ and $61 \%$ following the liquid mixed meal $(10 \mathrm{ml} / \mathrm{kg})$ in conscious and anaesthetized rats, respectively. Glucose, sucrose and water did not effectively activate MIS. MIS was completely reversed in the conscious model by atropine and completely prevented from developing in the anaesthetized model that had previously undergone hepatic denervation. Gastric administration of a liquid mixed meal but not glucose or sucrose is capable of activating MIS for purposes of mechanistic studies and quantification of the MIS process. The feeding signal is mediated by the hepatic parasympathetic nerves.
\end{abstract}

HISS: RIST: Insulin sensitivity: Meal: Feeding: Sucrose: Glucose

In the immediate post-meal state, insulin causes the release of a hormone, hepatic insulin sensitizing substance (HISS), from the liver. HISS and meal-induced insulin sensitization (MIS) have been reviewed previously (Lautt, 1999, 2003a). The hepatic parasympathetic nerves determine, in a permissive manner, the ability of insulin to cause HISS release. HISS action accounts for $55 \%$ of the glucose disposal effect following insulin administration in the post-meal state. The remaining $45 \%$ is accounted for by the direct action of insulin and is referred to as the HISS-independent component of insulin action. HISS is not released in the fasted state but becomes maximally releasable within $90 \mathrm{~min}$ of eating. HISS acts selectively on skeletal muscle to stimulate glucose uptake. The release of HISS results in MIS. MIS can be blocked by surgical and/or pharmacological interruption of the hepatic parasympathetic nerves (Xie et al. 1993; Xie \& Lautt, 1995), hepatic nitric oxide inhibition (Sadri \& Lautt, 1999), hepatic cyclooxygenase inhibition (Sadri \& Lautt, 2000) or depletion of hepatic glutathione (Guarino et al. 2003) leading to a state of HISS-dependent insulin resistance.

The response to insulin progressively decreases with the duration of fasting. In the absence of the hepatic parasympathetic permissive signal, as occurs during fasting, insulin does not result in significant HISS release. HISS release is therefore physiologically regulated so that in the post-meal state, rapid glucose uptake protects against the harmful effects of the postmeal glucose spike. In the fasted state, insulin, which continues to be released for other purposes, does not cause HISS release, thus minimizing the risk of hypoglycaemia.

We have shown that consumption of a solid meal (standard laboratory rat food) reverses HISS-dependent insulin resistance in $24 \mathrm{~h}$ fasted conscious unrestrained rats (Latour \& Lautt, 2002). In their study, the amount of the meal that was ingested and the duration of the consumption of the meal were unable to be standardized. We attempted to standardize the amount of the meal and the time allowed for the consumption of the meal by gavaging $24 \mathrm{~h}$ fasted rats with a liquid meal. However, the act of gavaging, even with water, led to hyperglycaemia, suggesting activation of a significant stress response (unpublished results). To overcome these limitations, we developed the current new methodology in which a liquid mixed meal is directly injected into the stomach via a gastric cannula and blood sampling is via an exteriorized arterialvenous shunt (AV shunt). In this manner, the volume and

Abbreviations: AV, shunt, arterial-venous shunt; HISS, hepatic insulin sensitizing substance; MIS, meal-induced insulin sensitisation; RIST, rapid insulin sensitivity test.

* Corresponding author: Dr W. Wayne Lautt, fax +1 204975 7784, email wlautt@cc.umanitoba.ca 
the duration of the injection of the meal can be standardized and multiple blood samples obtained.

In the present study we have examined the ability of a liquid mixed meal and D-glucose to trigger MIS in conscious rats. The effects of a mixed liquid meal, D-glucose, sucrose and distilled water on MIS were also studied in anaesthetized rats. The anaesthetized model was used to determine if the MIS occurs under anaesthesia in order to assess the feasibility of using the much less complex anaesthetized model for mechanistic studies of the MIS regulatory process.

\section{Materials and methods}

Animals were treated according to the guidelines of the Canadian Council on Animal Care, and the Ethics Committee on Animal Care at the University of Manitoba approved all protocols.

\section{The conscious model}

Surgical preparation. The surgical preparation previously described (Latour \& Lautt, 2002) was modified to include a gastric cannulation. Male Sprague-Dawley rats housed in climate-controlled conditions were fasted for $18 \mathrm{~h}$ prior to any surgical interventions. All instruments and cannulas were sterilized with Germex (MTC Pharmaceuticals, Cambridge, Ontario, Canada). The skin was shaved and washed with Hibitane (chlorhexidine gluconate 4\% (w/v); Ayerst Laboratories, Montreal, Canada), $70 \%$ ethanol and Betadine (10\% Povidoen-Iodine). After the rats were anaesthetized with isofluorane (1-5\% inspired, Aerrane) they were injected subcutaneously with Ketoprofen $(2.5 \mathrm{mg} / \mathrm{kg}$; Merial Canada Inc., Baie d'Urfé, Quebec, Canada). After the laparotomy, the gastric catheter (PE100 polyethylene tubing; Becton Dickinson, Sparks, MD, USA) was subcutaneously tunnelled behind the shoulder blades of the animal and implanted into the stomach using a purse-string suture (3-0 Dexon II; Tyco Healthcare Group LP, Norwalk, CT, USA). To ensure that the insertion site was sealed, a drop of surgical glue (GluStitch; GluStitch Inc., Delta, British Columbia, Canada) was used. The gastric cannula was filled with sterilized water. The right carotid artery and the left jugular vein were cannulated using Micro-Renathane ${ }^{\circledR} 40$ (MRE-040; Braintree Scientific, Braintree, MA, USA). Both catheters were soaked in heparin $(1000 \mathrm{IU} / \mathrm{ml})$ for $24 \mathrm{~h}$ prior to the surgery. After the catheters were subcutaneously tunnelled behind the shoulder blades and exteriorized, they were filled with heparin $(1000 \mathrm{IU} / \mathrm{ml})$. The catheters were then advanced towards the heart between 2.5 (carotid) and $3.0 \mathrm{~cm}$ (jugular) from the entry point and were tied and glued into place. At the end of the surgery, all skin openings were closed with sutures (3-0 Dexon II). The animals were allowed to recover for $4-7 \mathrm{~d}$ and had resumed normal feeding and weight gain prior to any experimentation.

Animal preparation. Animal preparation prior to the experiment, including the establishment of the AV shunt, was as previously described (Latour \& Lautt, 2002). Briefly, the rats were fasted for $24 \mathrm{~h}$ prior to the experiment. An AV shunt was established by connecting the carotid artery cannula to the jugular vein cannula by using silicone tubing (Masterflex; Cole-Parmer Instrument Co., Venon Hills, IL, USA) to allow blood to flow uninterrupted from the carotid artery to the jugular vein; a junction was inserted to allow pressure monitoring. Blood pressure was measured by clamping the silicon tubing on the venous side of the shunt. All drugs, glucose and fluids were administered into the AV shunt. After 30 min of stabilization, blood samples $(25 \mu \mathrm{l})$ were taken at 5 min intervals from the AV shunt and analysed for blood glucose concentration using the glucose oxidase method (Yellow Springs Instruments, Yellow Springs, OH, USA) until a minimum of three successive stable measurements $(< \pm 4 \mathrm{mg} \%)$ were obtained. The mean of these three samples was used as the basal glucose level.

Rapid insulin sensitivity test methodology. A modified rapid insulin sensitivity test (RIST) methodology to assess insulin sensitivity in conscious rats has been previously described (Latour \& Lautt, 2002). During the RIST, $50 \mathrm{mU} / \mathrm{kg}$ $(0.5 \mathrm{ml})$ insulin was delivered over $30 \mathrm{~s}$ into the venous side of the AV shunt. A variable glucose infusion, using a variable infusion pump ('Genie'; Kent Scientific Corporation, Litchfield, MA, USA), was initiated at $1 \mathrm{~min}$ and adjusted to maintain euglycaemia, based on the glucose concentration of blood samples taken every $2 \mathrm{~min}$. The quantification of insulin sensitivity is the amount of glucose infused to maintain euglycaemia in response to insulin, and is expressed as the RIST index ( $\mathrm{mg}$ glucose $/ \mathrm{kg}$ body weight).

Feeding in conscious rats. A control RIST was performed to assess the fasting insulin sensitivity in each animal. Upon completion, the animal received either $10 \mathrm{ml} / \mathrm{kg}$ of a liquid mixed meal (Boost ${ }^{\circledR}$; Mead Johnson Nutritionals, Ottawa, Ontario; protein $10 \mathrm{~g}$ per $237 \mathrm{ml}$; fat $4 \mathrm{~g}$ per $237 \mathrm{ml}$; carbohydrates $41 \mathrm{~g}$ per $237 \mathrm{ml}$; carbohydrate content $0.173 \mathrm{~g} / \mathrm{ml}$ ) or $10 \mathrm{ml} / \mathrm{kg}$ D-glucose $(0.173 \mathrm{~g} / \mathrm{ml})$ via the gastric catheter at a rate of $1 \mathrm{ml} / \mathrm{min}$. After $90 \mathrm{~min}$, when arterial glucose levels had been stable for at least $15 \mathrm{~min}$, a second RIST was performed to assess the change in insulin sensitivity due to MIS. After completion of the second RIST, atropine $(1.0 \mathrm{mg} / \mathrm{kg})$ was infused intravenously via the AV shunt to block HISS release. After stabilization of the blood glucose levels a third RIST was performed.

\section{The anaesthetized model}

Surgical preparation. Male Sprague-Dawley rats housed in climate-controlled conditions were fasted for $24 \mathrm{~h}$ prior to experimentation. The animals were weighed and anaesthetized by an intraperitoneal injection of pentobarbital sodium $(65 \mathrm{mg} / \mathrm{ml}$, Somnotol; Biomeda-MTC Animal Health Inc., Cambridge, Canada). Body temperature was monitored by a rectal probe and kept at $37.5 \pm 0.5^{\circ} \mathrm{C}$ by means of a heated surgical table and overhead lamp. The right femoral artery and vein were cannulated with catheters (PE60 polyethylene tubing; Becton Dickinson) that were part of an AV shunt that allowed blood to flow uninterrupted from the artery to the vein and blood pressure to be monitored (Lautt et al. 1998). Blood samples were taken by puncturing the arterial side of the shunt. Infusion of pharmacological agents was into the venous side of the shunt. Blood pressure was measured by clamping the silicon sleeve on the venous side of the shunt. Animals were heparinized (100 IU/kg) to prevent clotting in the shunt. The trachea was cannulated and the animal was allowed to breathe spontaneously. The left jugular 
vein was cannulated (PE60 polyethylene tubing) for a continuous supplemental sodium pentobarbital $(2.16 \mathrm{mg} / \mathrm{ml})$ infusion at a rate of $0.5 \mathrm{ml} / \mathrm{h}$ per $100 \mathrm{~g}$ body weight. A variable glucose infusion line was inserted into a silicon sleeve on the jugular supplement line and was controlled by an infusion pump (either Harvard Clinical; Harvard Clinical Technology Inc., South Natick, MA, USA; or 'Genie'). A laparotomy was performed and a 22G-1 inch catheter was inserted and glued into the stomach for feeding. In some animals an anterior hepatic plexus denervation was also performed. Upon completion of the surgery the animal was allowed to stabilize for $30 \mathrm{~min}$, at which time a blood sample $(25 \mu \mathrm{l})$ was taken and analysed for blood glucose concentration using the glucose oxidase method. Blood sampling continued every 5 min until a minimum of three successive stable measurements were taken. The mean of these three samples was used as the basal glucose level.

RIST methodology. The RIST methodology was used to assess insulin sensitivity as described earlier and previously (Lautt et al. 1998).

Feeding in the anaesthetized rats. After completion of a control RIST the animal received one of seven different 'meals' via the gastric catheter at a rate of $1 \mathrm{ml} / \mathrm{min}$ : 10 and $20 \mathrm{ml} / \mathrm{kg}$ of the liquid mixed meal, 10 and $20 \mathrm{ml} / \mathrm{kg}$ D-glucose $(0.173 \mathrm{~g} / \mathrm{ml}), 10$ and $20 \mathrm{ml}$ sucrose $(0.329 \mathrm{~g} / \mathrm{ml})$, or $20 \mathrm{ml} / \mathrm{kg}$ distilled water. After $90 \mathrm{~min}$, when arterial glucose levels had been stable for at least $15 \mathrm{~min}$, a second RIST was performed to assess the change in insulin sensitivity due to MIS.

Feeding in the denervated rats. An anterior hepatic plexus denervation was performed during the surgical preparation in these animals. A RIST was performed to assess the fasting insulin sensitivity. Upon completion, the animal received $10 \mathrm{ml} / \mathrm{kg}$ of liquid mixed meal via the gastric catheter at a rate of $1 \mathrm{ml} / \mathrm{min}$. After $90 \mathrm{~min}$, when arterial glucose levels had been stable for at least $15 \mathrm{~min}$, a second RIST was performed to assess the change in insulin sensitivity due to MIS in the absence of hepatic parasympathetic innervation.

\section{Drugs}

Human insulin (Humulin R) was purchased from Eli Lilly and Company (Toronto, Canada). D-Glucose and sucrose were purchased from Sigma Chemical Co. (St. Louis, MO, USA). All drugs were dissolved in saline. The sucrose and D-glucose used for feeding were dissolved in double-distilled water.

\section{Data analysis}

Data were analysed using the repeated measures ANOVA followed by Tukey-Kramer multiple comparison test in each group or, when applicable, the paired and unpaired Student's $t$-test. The data are expressed as means and their standard errors throughout. Differences were accepted as statistically significant at $P<0 \cdot 05$.

\section{Results}

\section{The conscious model}

Liquid mixed meal. Rats ( 6 6; 258.2 (SE 5.7) g) receiving $10 \mathrm{ml} / \mathrm{kg}$ of liquid mixed meal had a fasting RIST index of

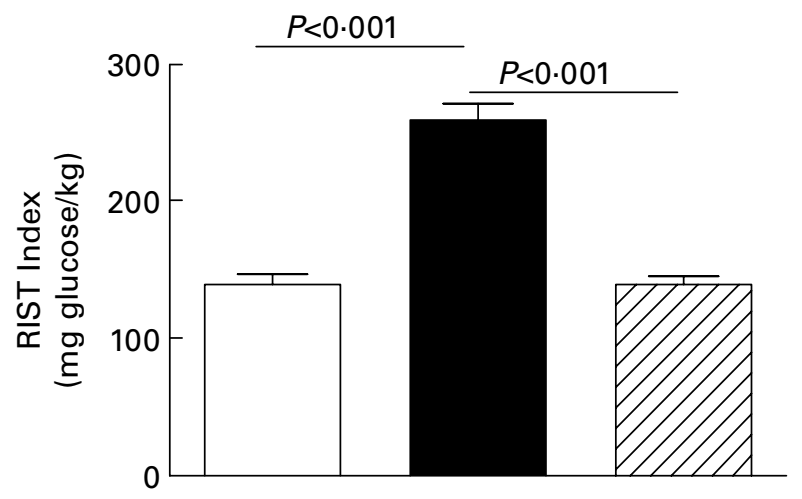

Fig. 1. The response to insulin administration in conscious, unrestrained rats tested using the rapid insulin sensitivity test (RIST) was increased from control $(\square)$ by 90.5 (SE 20) \% after the liquid mixed meal (10 ml $/ \mathrm{kg}, \mathbf{\square}$ ). Atropine $(1.0 \mathrm{mg} / \mathrm{kg}, \mathbb{2})$, which blocks hepatic insulin sensitizing substance release, completely eliminated the meal-induced insulin sensitization. For details of procedures, see p. 289. Values are means with their standard errors depicted by vertical bars $(n 6)$.

138.8 (SE 8.9) $\mathrm{mg}$ glucose/kg (Fig. 1). After feeding with the liquid mixed meal the RIST index was significantly $(P<0.001)$ potentiated, 90.5 (SE 20.5) \%, to 259.0 (SE 13.8) $\mathrm{mg}$ glucose/kg. Blood glucose levels at $90 \mathrm{~min}$ after feeding, just prior to the RIST, were 115.8 (SE 3.6) $\mathrm{mg} / \mathrm{dl}$ and blood pressure was 88.0 (SE 5.5) $\mathrm{mmHg}$. Administration of atropine significantly $(P<0 \cdot 001)$ inhibited the RIST index to $139 \cdot 2$ (SE 6.9) $\mathrm{mg} / \mathrm{kg}$ which was not different from the fasting RIST index. Blood pressure and glycaemia were not altered by atropine. This indicates that the liquid mixed meal is capable of producing MIS and that blockade of the parasympathetic nerves completely blocks MIS.

$D$-Glucose. Rats (n 7; 260.9 (SE 5.0) g) receiving $10 \mathrm{ml} / \mathrm{kg}$ of D-glucose had a fasting RIST index of 119.9 (SE 8.1) $\mathrm{mg}$ glucose/kg (Fig. 2). After feeding with the D-glucose the RIST index was only potentiated by 27.7 (SE 15.5) \% to $152 \cdot 8$ (SE 20.1) $\mathrm{mg}$ glucose/kg (NS). Blood glucose levels at $90 \mathrm{~min}$ post-feeding and just prior to the RIST were $121 \cdot 1$ (SE 9.9) $\mathrm{mg} / \mathrm{dl}$ and blood pressure was 79.4 (SE 3.8) $\mathrm{mmHg}$.

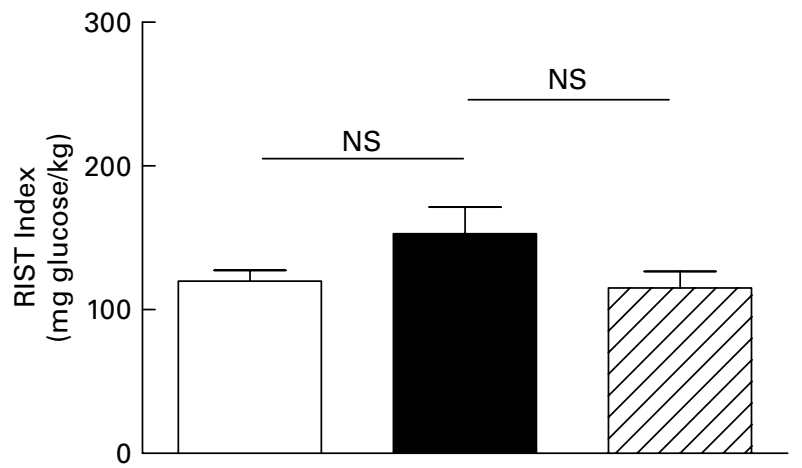

Fig. 2. D-Glucose $(10 \mathrm{ml} / \mathrm{kg}, \square)$ administered to conscious rats did not produce a significant meal-induced insulin sensitization (control, $\mathbf{\square})$ and atropine $(1.0 \mathrm{mg} / \mathrm{kg}$, which blocks hepatic insulin sensitizing substance release, did not significantly decrease the response, indicating that glucose is incapable of serving as a meal signal for meal-induced insulin sensitization. For details of procedures, see p. 289. Values are means with their standard errors depicted by vertical bars $(n 7)$. 


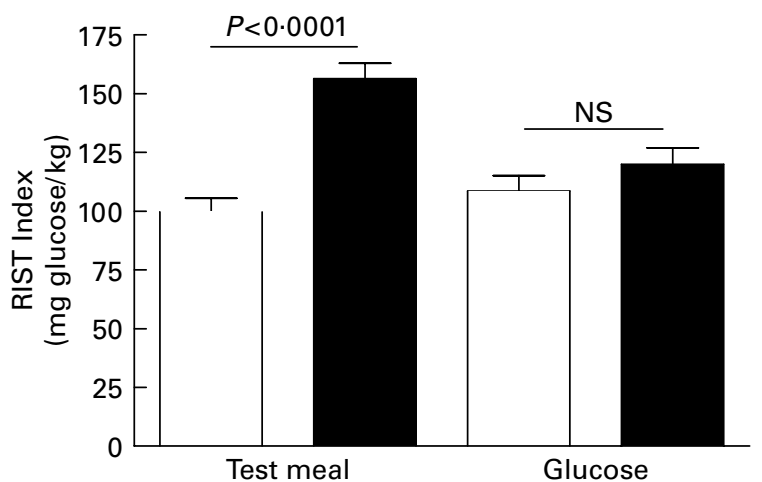

Fig. 3. Meal-induced insulin sensitization is confirmed in the anaesthetized rat model in response to a liquid mixed meal $(n 9)$ and it is further confirmed in a separate group $(n 6)$ that glucose is incapable of causing meal-induced insulin sensitization. $\square$, Control; $\mathbf{\square}$, post-feeding $(10 \mathrm{ml} / \mathrm{kg})$. For details of procedures, see p. 289. Values are means with their standard errors depicted by vertical bars.

Administration of atropine did not significantly inhibit the RIST index (115.0 (SE 12.6) mg/kg).

\section{The anaesthetized model}

Liquid mixed meal administration at $10 \mathrm{ml} / \mathrm{kg}$. Rats ( $\mathrm{n} 9$; 255.7 (SE 3.2) g) receiving $10 \mathrm{ml} / \mathrm{kg}$ of liquid mixed meal had a fasting RIST index of 99.6 (SE 5.8) $\mathrm{mg}$ glucose $/ \mathrm{kg}$ (Fig. 3). After feeding with the liquid mixed meal the RIST index was significantly $(P<0.001)$ potentiated, 60.7 (SE 11.0 ) $\%$, to $156 \cdot 3$ (SE 6.6) $\mathrm{mg}$ glucose $/ \mathrm{kg}$. Blood glucose levels at $90 \mathrm{~min}$ post-feeding and just prior to the RIST were 103.4 (SE 2.2) $\mathrm{mg} / \mathrm{dl}$ and blood pressure was 88.8 (SE 4.4) $\mathrm{mmHg}$.

D-Glucose administration at $10 \mathrm{ml} / \mathrm{kg}$. Rats $(n 6 ; 262.1$ (SE 7.4) g) receiving $10 \mathrm{ml} / \mathrm{kg}$ of D-glucose had a fasting RIST index of 108.5 (SE 6.6) $\mathrm{mg}$ glucose/kg (Fig. 3). After feeding with D-glucose the RIST index was only potentiated 12.9

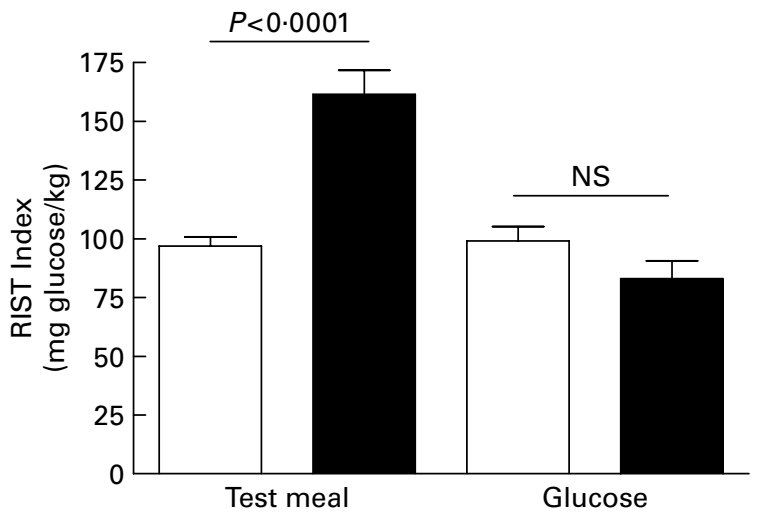

Fig. 4. Attempts to provide a larger feeding signal by doubling the volume of the liquid mixed meal and glucose load compared to the data shown in Fig. 3 was unsuccessful. The liquid mixed meal resulted in a 67.0 (SE 9.4) \% sensitization to insulin administration ( $n$ 11) and the glucose produced no tendency for insulin sensitization ( $n$ 6). $\square$, Control; $\boldsymbol{\square}$, post-feeding $(20 \mathrm{ml} / \mathrm{kg})$. For details of procedures, see p. 289. Values are means with their standard errors depicted by vertical bars.
(SE 11.2 ) \% to 119.9 (SE 7.1) mg glucose/kg (NS). Blood glucose levels at 90 min post-feeding and just prior to the RIST were 107.9 (SE 4.3) $\mathrm{mg} / \mathrm{dl}$ and blood pressure was 91.2 (SE 5.6) $\mathrm{mmHg}$.

Liquid mixed meal administration at $20 \mathrm{ml} / \mathrm{kg}$. Rats $(\mathrm{n} 11$; 264.2 (SE 6.6) g) receiving $20 \mathrm{ml} / \mathrm{kg}$ of liquid mixed meal had a fasting RIST index of 96.8 (SE 4.1) $\mathrm{mg}$ glucose/kg (Fig. 4). After feeding with the liquid mixed meal the RIST index was significantly $(P<0.0001)$ potentiated, 67.0 (SE 9.4) \%, to 161.5 (SE 10.2) $\mathrm{mg}$ glucose/kg. Blood glucose levels at $90 \mathrm{~min}$ post-feeding and just prior to the RIST were $106.8(\mathrm{SE} 2 \cdot 2) \mathrm{mg} / \mathrm{dl}$ and blood pressure was 85.6 (SE 2.2) $\mathrm{mmHg}$.

D-Glucose administration at $20 \mathrm{ml} / \mathrm{kg}$. Rats (n 6; 241.6 (SE 3.6) g) receiving $20 \mathrm{ml} / \mathrm{kg}$ of D-glucose had a fasting RIST index of 99.2 (SE 6.0) $\mathrm{mg}$ glucose/kg (Fig. 4). After feeding with D-glucose the RIST index was decreased 15.2 (SE 9.7) \% to 83.0 (SE 7.6) $\mathrm{mg}$ glucose $/ \mathrm{kg}$ (NS). Blood glucose levels at $90 \mathrm{~min}$ post-feeding and just prior to the RIST were 121.0 (SE 6.3) $\mathrm{mg} / \mathrm{dl}$ and blood pressure was 93.5 (SE 5.4) $\mathrm{mmHg}$.

Thus, D-glucose administration at 10 or $20 \mathrm{ml} / \mathrm{kg}$ is not capable of initiating MIS.

Sucrose administration. Rats ( $n$ 6; 273.6 (SE 13.1) g) receiving $10 \mathrm{ml} / \mathrm{kg}$ of sucrose had a fasting RIST index of 97.5 (SE 4.3) mg glucose/kg (Fig. 5). After feeding with sucrose the RIST index was only potentiated 11.1 (SE 2.3) $\%$ to 107.1 (SE 4.9) $\mathrm{mg}$ glucose/kg (NS). Blood glucose levels at $90 \mathrm{~min}$ post-feeding and just prior to the RIST were 104.9 (SE 2.3) $\mathrm{mg} / \mathrm{dl}$ and blood pressure was 91.5 (SE 4.0) $\mathrm{mmHg}$.

Rats ( $7 ; 250 \cdot 1$ (SE 5.5) g) receiving $20 \mathrm{ml} / \mathrm{kg}$ of sucrose had a fasting RIST index of 103.2 (SE 5.4) mg glucose $/ \mathrm{kg}$ (Fig. 5). After feeding with sucrose the RIST index was significantly $(P<0.05)$ potentiated, 17.3 (SE 4.6$) \%$, to 120.9 (SE 9.5) $\mathrm{mg}$ glucose $/ \mathrm{kg}$. Blood glucose levels at $90 \mathrm{~min}$ postfeeding and just prior to the RIST were 115.9 (SE 4.7) $\mathrm{mg} / \mathrm{dl}$ and blood pressure was 90.7 (SE 4.8) $\mathrm{mmHg}$.

Water administration. Rats $(n 7 ; 266.7$ (SE 6.3) g) receiving $20 \mathrm{ml} / \mathrm{kg}$ of distilled water had a fasting RIST index of 93.9 (SE 4.9) $\mathrm{mg}$ glucose/kg (Fig. 6). After feeding with

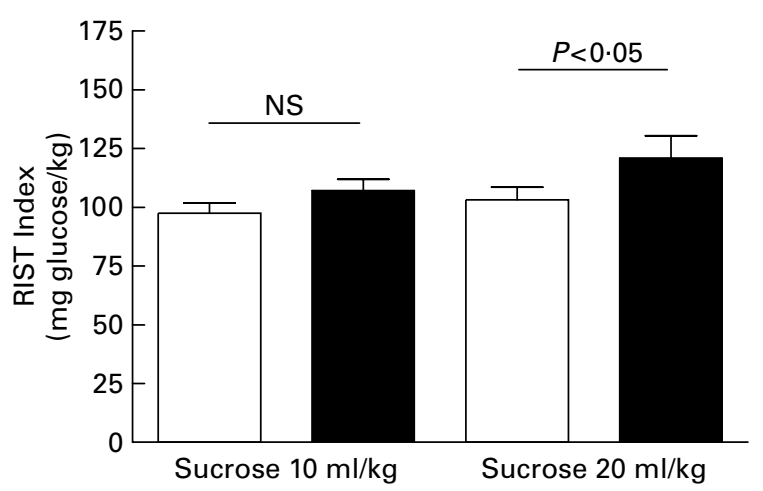

Fig. 5. Sucrose was ineffective in producing meal-induced insulin sensitization at the lower volume $(n 6)$ and only mildly effective in a separate group $(n 7)$ at the doubled volume, demonstrating that sucrose is very ineffective at stimulating the meal signal. $\square$, Control; $\mathbf{\square}$, post-sucrose. For details of procedures, see p. 289. Values are means with their standard errors depicted by vertical bars. 


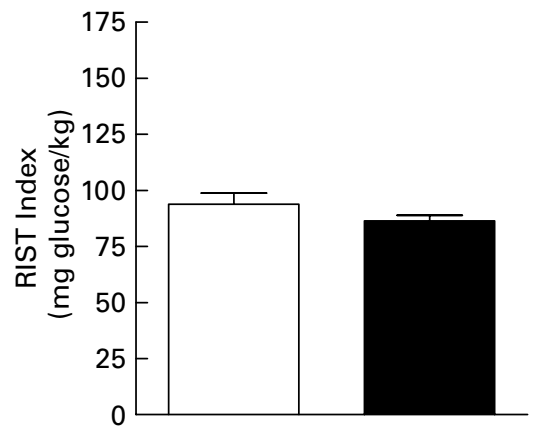

Fig. 6. Water administered at $20 \mathrm{ml} / \mathrm{kg}$ volume was not capable of serving as a feeding signal. $\square$, Control; $\mathbf{\square}$, post-water. For details of procedures, see p. 289. Values are means with their standard errors depicted by vertical bars $(n 7)$

water the RIST index was decreased to a very minor, but statistically significant, extent $(P<0 \cdot 05)-7 \cdot 1$ (SE 3.2) \% to $86 \cdot 5$ (SE 2.4) $\mathrm{mg}$ glucose $/ \mathrm{kg}$. Blood glucose levels at $90 \mathrm{~min}$ post-feeding and just prior to the RIST were 87.2 (SE 5.2) $\mathrm{mg} / \mathrm{dl}$ and blood pressure was 85.9 (SE 4.1) $\mathrm{mmHg}$.

Liquid mixed meal in the hepatic denervated animal. Rats ( $n$ 7; 249.3 (SE 4.4) g) in this group had a fasting RIST index of 107.9 (SE 6.7) mg glucose/kg (Fig. 7). After feeding with $10 \mathrm{ml} / \mathrm{kg}$ of the liquid mixed meal the RIST index did not change significantly (102.5 (SE 8.5) mg glucose/kg). Blood glucose levels at $90 \mathrm{~min}$ post-feeding and just prior to the RIST were 103.2 (SE 1.7) $\mathrm{mg} / \mathrm{dl}$ and blood pressure was 78.0 (SE 4.6) $\mathrm{mmHg}$. The hepatic parasympathetic nerves are necessary for MIS.

Summary of percentage meal-induced insulin sensitisation. Fig. 8 summarizes the percentage MIS obtained using all eight feeding groups in anaesthetized rats and emphasizes that only the mixed meal results in biologically significant MIS. Further, the lower degree of MIS seen in the anaesthetized rat was not because of inadequate meal volume or caloric load since doubling the meal size did not produce a greater degree of MIS.

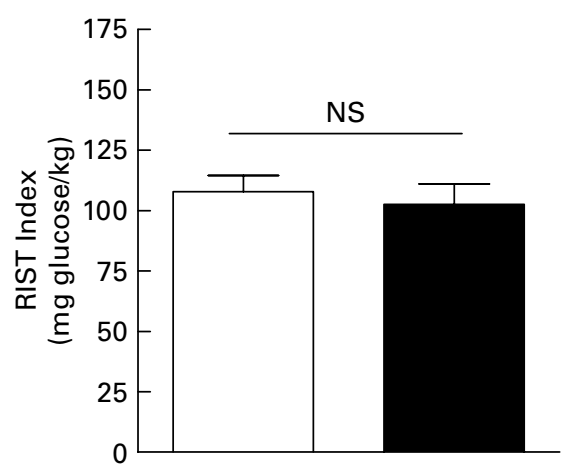

Fig. 7. Denervation of the liver at the anterior plexus completely prevented the liquid mixed meal from inducing meal-induced insulin sensitization thereby confirming the requirement of intact hepatic parasympathetic nerves for transmitting the feeding signal to the liver. $\square$, Control with anterior plexus denervation; $\mathbf{\square}$, post-feeding $(10 \mathrm{ml} / \mathrm{kg})$. For details of procedures, see p. 289. Values are means with their standard errors depicted by vertical bars $(n 7)$.

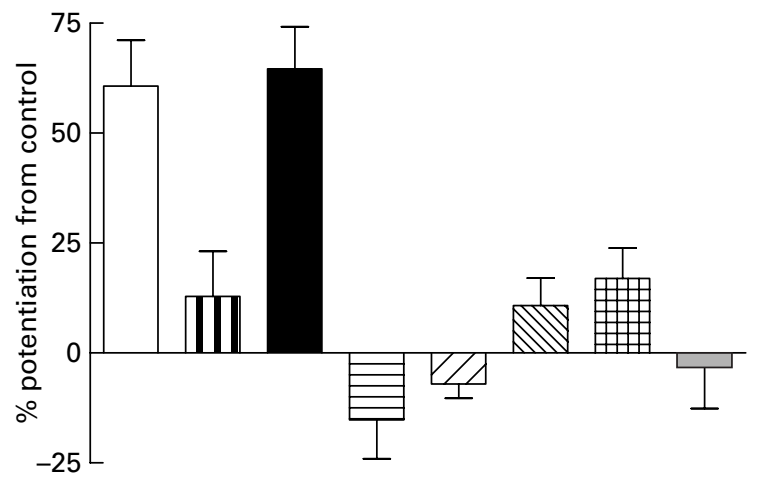

Fig. 8. Summary of the percentage meal-induced insulin sensitization produced by the various meals and volumes in anaesthetized rats, indicating that only the mixed liquid test meals produced effective meal-induced insulin sensitization. Glucose and sucrose and water were ineffective or weakly effective at activating meal-induced insulin sensitization. $\square$, Test meal $(10 \mathrm{ml} / \mathrm{kg}, n$ 9); 四, glucose $(10 \mathrm{ml} / \mathrm{kg}, n 6) ; \mathbf{\square}$, test meal $(20 \mathrm{ml} / \mathrm{kg}, n 11)$; 苜, glucose $(20 \mathrm{ml} / \mathrm{kg}, n 6)$; $\mathbb{2}$, water $(20 \mathrm{ml} / \mathrm{kg}, n 7) ; \mathbb{Q}$, sucrose $(10 \mathrm{ml} / \mathrm{kg}, n 6)$; 耚, sucrose $(20 \mathrm{ml} / \mathrm{kg}, n 7)$; , denervated $/ \mathrm{meal}(10 \mathrm{ml} / \mathrm{kg}, n 7)$. For details of procedures, see p. 289. Values are means with their standard errors depicted by vertical bars.

\section{Discussion}

The liquid mixed meal significantly induced MIS in both anaesthetized and conscious rats. Surgical denervation of the hepatic parasympathetic nerves inhibited MIS induction by the liquid mixed meal. D-Glucose and the low-dose sucrose administrations failed to induce MIS. However, a higher dose of sucrose did significantly potentiate MIS, but not to the extent of the liquid mixed meal. Administration of water, as a volume control, decreased MIS to a very minor extent.

MIS occurs within 90 min of consumption of a mixed meal. For MIS to occur, a permissive feeding signal must be delivered to the liver through parasympathetic nerves, mediated by cholinergic muscarinic receptor activation and generation of nitric oxide. Against this background of permissive nerve signal, pulses of insulin cause the pulsatile release of a hormone from the liver, tentatively referred to as HISS, which acts selectively on skeletal muscle to stimulate glucose uptake. HISS release occurs in the fed state and its release in response to insulin decreases progressively to insignificance by a $24 \mathrm{~h}$ period of fasting. HISS action accounts for the increased response to insulin seen following a meal. The most straightforward method to quantitate MIS is to compare insulin sensitivity in the fasted state with the same determinations in the fed state. Alternatively, MIS can be readily quantified by determining insulin sensitivity in the fed state and then tested again after the parasympathetic signal has been eliminated by surgical denervation of the liver, or atropine blockade of hepatic muscarinic receptors, or inhibition of hepatic nitric oxide production (reviewed by Lautt, 1999; Lautt, 2003a).

While these procedures are quite suitable for some types of mechanistic studies, they are not well suited for studies designed to understand the characteristics of a meal that leads to MIS. For this reason, we developed the present models that utilize a gastric injection of a liquid mixed meal in both a conscious and anaesthetized rat model. The rationale 
for development of the injected liquid mixed meal is that animals who are instrumented and have insulin sensitivity tested in the fasted state do not consistently voluntarily consume a solid meal of standard volume within a brief standardized period of time. The solid test meal administered in the conscious state resulted in a RIST index of $239 \mathrm{mg}$ glucose $/ \mathrm{kg}$ when tested in the conscious rat and $225 \mathrm{mg}$ glucose $/ \mathrm{kg}$ when tested after anaesthesia (Latour \& Lautt, 2002). Similarly, in the current study, the liquid mixed meal injected into the stomach of conscious rats resulted in a $91 \%$ potentiation of insulin sensitivity and a RIST index of $259 \mathrm{mg}$ glucose $/ \mathrm{kg}$ (Fig. 1). MIS was shown to be mediated by a parasympathetic signal through the demonstration of a complete blockade of the MIS following treatment of the animal with atropine. This atropine blockade resulted in insulin sensitivity in the fed animal that was equivalent to that of a fasted animal. The conscious rat model using gastric injection of a liquid mixed meal is a useful model to study MIS.

Because the conscious animal model is considerably more difficult and requires higher maintenance, we also evaluated whether the MIS could be generated in an animal that was anaesthetized. Although the degree of MIS was less than that seen in the conscious animal, the $61 \%$ increase in insulin sensitivity (Fig. 3) allows for convenient mechanistic studies to evaluate the impact of meal composition on the MIS process. In both the conscious and anaesthetized animals, the liquid mixed meal produced MIS but glucose and sucrose proved ineffective or very weak activators of the feeding signal.

\section{Quantification of meal-induced insulin sensitization}

In order to quantitate MIS, which is HISS-dependent, HISSdependent insulin action must be able to be measured. Methodological considerations have previously been reviewed (Lautt, 2003b) and it has been shown that HISS action can be quantified using the insulin tolerance test (Reid et al. 2002), arterial-venous glucose gradients across vascular beds (Xie \& Lautt, 1996; Moore et al. 2002) and the RIST. In contrast, insulin administered in a continuous manner in rats is not only incapable of determining HISS action but actually leads to blockade of HISS release when tested after a period of 60 min or more of continuous infusion (Reid \& Lautt, 2004).

The RIST is used throughout and is the recommended method for quantification of HISS-dependent and HISS-independent insulin action because the transient euglycaemic clamp prevents hypoglycaemia from occurring in response to insulin administration and is reproducible four times in the same animal over an $8 \mathrm{~h}$ period in the anaesthetized state (Lautt et al. 1998). It is also sufficiently quantitative to allow for dose-response studies, for example showing atropine dose-dependent HISS-dependent insulin resistance (Takayama et al. 2000).

\section{The conscious $v$. anaesthetized model}

The conscious model, although more complex and requiring higher maintenance, was well tolerated and there was no behavioural impact noted during the RIST in either the fasted or fed state, and administration of $10 \mathrm{ml} / \mathrm{kg}$ liquid mixed meals produced no notable behavioural responses. The RIST index in the conscious rat model increased from $139 \mathrm{mg}$ glucose $/ \mathrm{kg}$ to $259 \mathrm{mg}$ glucose $/ \mathrm{kg}$ and atropine resulted in a return of the RIST index to $139 \mathrm{mg}$ glucose $/ \mathrm{kg}$ (Fig. 1). Animals fed solid chow in the conscious state and then anaesthetized and subjected to the RIST show RIST indexes averaging approximately $235 \mathrm{mg}$ glucose $/ \mathrm{kg}$ and HISSindependent insulin action of approximately $100 \mathrm{mg}$ glucose/ $\mathrm{kg}$ (Lautt et al. 2001). Therefore, the liquid mixed meal administered by gastric injection is a useful means of inducing a normal degree of MIS and avoids the problem of the need for voluntary consumption of a solid meal within a limited period of time and it eliminates the stress of a gavage.

Although MIS can be quantified in the anaesthetized model, the anaesthetic clearly has an impact. The anaesthetic impact does not appear to be on the RIST as animals fed and then tested either in the conscious state or after anaesthesia show similar RIST indexes. The impact would appear most likely to be related to impairment of the feeding signal. In order for insulin to cause HISS release, hepatic parasympathetic nerves produce a permissive signal acting through muscarinic cholinergic receptors in the liver mediated by nitric oxide production. The effector arm of this regulatory process has been investigated but the afferent end has not. It is known that feeding causes MIS that decreases progressively with the duration of fasting in the conscious state. When tested $6 \mathrm{~h}$ after a meal, the conscious rat shows a substantial decrease in the RIST index from approximately $230 \mathrm{mg}$ glucose $/ \mathrm{kg}$ to $150 \mathrm{mg}$ glucose $/ \mathrm{kg}$ (Lautt et al. 2001). However, if the rat is fed in the conscious state and then anaesthetized, a normal fed RIST index is well sustained over $6-8 \mathrm{~h}$. The possibility that the feeding signal in the anaesthetized preparation was weak because of insufficient quantity of food was disproven by doubling the meal size with no significant increase in MIS.

\section{Glucose and sucrose do not provide an adequate feeding signal}

Glucose proved incapable of significantly activating MIS in either preparation. Sucrose was similarly ineffective with the low dose causing a MIS of $11 \%$ (NS) and a double dose causing $17 \%$ MIS $(P<0 \cdot 05)$. A volume control with water resulted in no MIS. Further studies are required to determine the effect of meal composition on MIS. Clearly glucose, sucrose or volume alone do not cause MIS (Fig. 8). It is not clear, however, if they interact with other nutrients to activate the MIS signal. The location of sensors is also not clear. A solid meal that remains in the stomach, as a result of gastrointestinal paralysis from anaesthesia, maintains the signal for hours. The liquid meal was injected into the stomach but postmortem examination showed that the meal had moved into the upper ileum. Nevertheless, it appears that the sensory signal is likely delivered from the stomach in response to specific elements of the meal. Although the magnitude of sensitization to insulin was less in the animals administered the meal while anaesthetized, the response is qualitatively sufficiently similar to that obtained in the conscious animal in order to be useful for mechanistic studies.

\section{Confirmation of parasympathetic regulation of meal-induced insulin sensitization}

Atropine has previously been demonstrated in numerous publications (e.g. Lautt et al. 2001) to result in complete 
elimination of the HISS-dependent response with the postatropine RIST index in fed animals being similar to that in fasted animals. Atropine does not impact on the HISSindependent component of insulin action. In the conscious animals, the RIST index increased from 139 to $257 \mathrm{mg}$ glucose $/ \mathrm{kg}$ after feeding and atropine resulted in a blockade of HISS release with the return of the RIST index to $139 \mathrm{mg}$ glucose $/ \mathrm{kg}$. The similarity of the fasted RIST index and the atropine-treated fed RIST index supports the use of atropine as a research tool in conscious animals in that it appears not to alter HISS-independent insulin action while blocking HISS release in a dose-dependent manner (Xie \& Lautt, 1995; Takayama et al. 2000). Similar dependence on the hepatic parasympathetic signal was demonstrated in the anaesthetized animals where surgical denervation was carried out prior to administration of the meal. The fasting RIST index of $108 \mathrm{mg}$ glucose $/ \mathrm{kg}$ was not significantly altered (103 mg glucose $/ \mathrm{kg}$ ) following administration of $10 \mathrm{ml} / \mathrm{kg}$ of the liquid mixed meal to rats with hepatic denervation (Fig. 7). These data confirm that the hepatic parasympathetic signal is essential for HISS-mediated MIS and that absence of the signal can prevent MIS from occurring and eliminate it once it has occurred.

\section{Nutritional implications}

The HISS hypothesis, which is fully reviewed elsewhere (Lautt, $1999,2003 a, b, 2004)$, is consistent with the following brief summary. Following a meal, insulin results in the release of HISS from the liver which acts selectively on skeletal muscle to stimulate glucose uptake and storage as glycogen. Lack of ability to release HISS results in a state of HISS-dependent insulin resistance which is a normal regulated state in the fasting condition but represents a pre-diabetic state when it occurs after feeding. In the absence of HISS release in the fed state, the response to insulin is reduced by approximately $55 \%$ so that increased insulin secretion is required to compensate for the postprandial hyperglycaemia. In the pre-diabetic state, the increased insulin stimulates glucose uptake in insulin-sensitive tissues, primarily adipose tissue and liver. In contrast to HISS, which results in glucose uptake primarily into skeletal muscle, insulin results in nutrient storage more as lipids. HISS-dependent insulin resistance accounts for the insulin resistance seen in a wide range of animal models including the spontaneously hypertensive rat, sucrose-fed rats, animals with liver disease induced by chronic bile duct ligation or chemical toxins, adult offspring of fetal alcohol exposure, acute stress and ageing, physical interruption of hepatic parasympathetic nerves, and pharmacological blockade of hepatic muscarinic cholinergic receptors or nitric oxide production or cyclooxygenase (reviewed Lautt, 2003a,b).

From a nutritional perspective, meals that are capable of producing MIS are advantageous whereas meals that cannot produce MIS will result in nutrients being processed primarily as fat. Glucose and sucrose clearly are ineffective at serving as an appropriate feeding signal. In addition, high-sucrose diets not only are not capable of activating MIS, but actually result in complete HISS-dependent insulin resistance after as short a period of feeding as 2 weeks on a $35 \%$ sucrose diet (Ribeiro et al. 2005). These observations may be directly related to the cause of the epidemic increase in insulin resistance, type 2 diabetes and obesity in developed countries where refined sugar products make up a very large component of the normal diet. The demonstration that MIS cannot be generated by these refined sugars places added emphasis on the need for studies related to nutrient content of meals, especially in highrisk groups.

\section{Conclusions}

MIS can clearly be quantitated in both the conscious and anaesthetized animal through the use of RIST to measure insulin sensitivity before and after administration of a liquid mixed meal of varying compositions. Whereas a mixed liquid meal results in significant and normal activation of MIS, albeit at a lower magnitude in the anaesthetized animal, the models are well suited for studies related to the impact of nutrient content on generation of MIS. Sucrose and glucose are not capable of producing normal feeding signals thereby questioning the value of the oral glucose tolerance test for studies intended to quantitate responses to feeding. Atropine is confirmed to completely reverse the MIS process and hepatic parasympathetic denervation to prevent its activation which is consistent with previous mechanistic studies related to the role and control of HISS.

\section{Acknowledgements}

This work was supported by an operating grant from the Canadian Institutes of Health Research to W. W. Lautt. P. Sadri was supported by an NSERC Postdoctoral Fellowship. R. A. Afonso was supported by a $\mathrm{PhD}$ Fellowship (SFRH/BD/ 9082/2002) from the Foundation for Science and Technology (FCT).

\section{References}

Guarino MP, Afonso RA, Raimundo N, Raposo JF \& Macedo MP (2003) Hepatic glutathione and nitric oxide are critical for hepatic insulin-sensitizing substance action. Am J Physiol Gastrointest Liver Physiol 284, G588-G594.

Latour MG \& Lautt WW (2002) Insulin sensitivity regulated by feeding in the conscious unrestrained rat. Autonom Neurosci 95, $125-130$.

Lautt WW (1999) The HISS story overview: a novel hepatic neurohumoral regulation of peripheral insulin sensitivity in health and diabetes. Can J Physiol Pharmacol 77, 553-562.

Lautt WW (2003a) A proposed new paradigm for insulin resistance. Metab Syndr Relat Dis 1, 261-270.

Lautt WW (2003b) Practice and principles of pharmacodynamic determination of HISS-dependent and HISS-independent insulin action: methods to quantitate mechanisms of insulin resistance. Med Res Rev 23, 1-14.

Lautt WW (2004) A new paradigm for diabetes and obesity: the hepatic insulin sensitizing substance (HISS) hypothesis. J Pharmacol Sci 95, 9-17.

Lautt WW, Macedo MP, Sadri P, Takayama S, Ramos FD \& Legare DJ (2001) Hepatic parasympathetic (HISS) control of insulin sensitivity determined by feeding and fasting. Am J Physiol Gastrointest Liver Physiol 281, G29-G36.

Lautt WW, Wang X, Sadri P, Legare DJ \& Macedo MP (1998) Rapid insulin sensitivity test (RIST). Can J Physiol Pharmacol 76, 1080-1086. 
Moore MC, Sataka S, Baranowski B, Hsieh P-S, Neal DW \& Cherrington AD (2002) Effect of hepatic denervation on peripheral insulin sensitivity in conscious dogs. Am J Physiol Endocrinol Metab 282, E286-E296.

Reid MAG, Latour MG, Legare DJ, Rong N \& Lautt WW (2002) Comparison of the rapid insulin sensitivity test (RIST), the insulin tolerance test (ITT), and the hyperinsulinemic clamp (HIEC) to measure insulin action in rats. Can J Physiol Pharmacol 80, 811-818.

Reid MAG \& Lautt WW (2004) Pattern of insulin delivery affects HISS action and insulin resistance. Can J Physiol Pharmacol 82, $1068-1074$.

Ribeiro RT, Lautt WW, Legare DJ \& Macedo MP (2005) Insulin resistance induced by sucrose-feeding is due to an impairment of the hepatic parasympathetic nerves. Diabetologia 48, 976-983.
Sadri P \& Lautt WW (1999) Blockade of hepatic nitric oxide synthase causes insulin resistance. Am J Physiol 277, G101-G108.

Sadri P \& Lautt WW (2000) Insulin resistance caused by hepatic COX inhibition (abstract). Diabetes 49, A245.

Takayama S, Legare DJ \& Lautt WW (2000) Dose-related atropineinduced insulin resistance: comparing intraportal versus intravenous administration. Proc West Pharmacol Soc 43, 33-34.

Xie H \& Lautt WW (1995) Induction of insulin resistance by cholinergic blockade with atropine in the cat. J Auton Pharmacol 15, 361-369.

Xie H \& Lautt WW (1996) Insulin resistance of skeletal muscle produced by hepatic parasympathetic interruption. Am J Physiol 270, E858-E863.

Xie H, Tsybenko VA, Johnson MV \& Lautt WW (1993) Insulin resistance of glucose response produced by hepatic denervations. Can J Physiol Pharmacol 71, 175-178. 